\title{
CHARACTERIZATION AND TREATMENT OF ODOROUS FOOD FERMENTATION PROCESS EMISSIONS VIA PILOT-SCALE BIOFILTER
}

\author{
ILKER AKMIRZA ${ }^{1}$, KADIR ALP $^{1}$, MUSTAFA TURKER $^{2}$, \\ SAADET ETLI ${ }^{1} \&$ MERVE YILMAZ ${ }^{1}$ \\ ${ }^{1}$ Environmental Engineering Department, Istanbul Technical University, Turkey \\ ${ }^{2}$ Pakmaya Baker's Yeast Factory, Turkey
}

\begin{abstract}
Recently, odor emissions have globally become an essential contamination parameter within increasing the well-being levels of human life. In order to control odor emissions and reduce their health and environmental effects, over the last decade Europe, USA and Turkey have started to enact regulations and investigations into suitable odor-treatment alternatives. Food fermentation is one of the important processes that releases odorous pollutants like ethanol, acetaldehyde, acetone and propanol to the atmosphere without any control mechanism. Until now, many physicochemical techniques have been used for the abatement of volatile organic compounds (VOCs). However, the high capital and operating costs associated with these technologies, their high energy requirements and non-environmentally friendly nature have boosted the development of new treatment technologies. In recent years, many biological treatment methods such as biofilters, bioscrubbers and biotrickling filters were found to be environmentally friendly and low-cost treatment alternatives for odorous compounds. Biofilters come into prominence above other biological treatment technologies due to their high flowrate waste gas treatment capacities. Within this scope of aim, VOC emissions derived from food fermentation processes were investigated on a pilot scale biofilter consisting of a cylindrical jacketed PVC column $(0.20 \mathrm{~m}$ inner diameter, $2.7 \mathrm{~m}$ height) packed with Rashing rings to a working volume of $50 \mathrm{~L}$. The synthetic inlet gas stream with a flowrate of $2 \mathrm{~m}^{-3} \mathrm{~h}^{-1}$ was prepared by injecting a liquid mixture containing emissions at inlet concentrations of $\sim 700 \mathrm{mg} \mathrm{m}^{-3}$ for ethanol, $\sim 300 \mathrm{mg} \mathrm{m}^{-3}$ for acetaldehyde and $\sim 70 \mathrm{mg} \mathrm{m}^{-3}$ for acetone according to waste gas characterization of industrial processes. Biodegradation of ethanol was achieved up to $29 \pm 1 \mathrm{~g} \mathrm{~m}^{-3} \mathrm{~h}^{-1}$ of elimination with a removal $>90 \%$ where $11.4 \pm 0.7 \mathrm{~g} \mathrm{~m}^{-3} \mathrm{~h}^{-1}$ acetaldehyde was eliminated with removal $>90 \%$. Acetone elimination was recorded as $1.9 \pm 0.3 \mathrm{~g} \mathrm{~m}^{-3} \mathrm{~h}^{-1}$ and resulted in the removal of $\sim 50 \%$.

Keywords: biofilter, emission, odor, treatment, food fermentation, characterization, VOCs.
\end{abstract}

\section{INTRODUCTION}

Increasing numbers in the human population also brings an increase in the demand for manufacture. As a result, within developing activities of the industries many emissions are released into the atmosphere. An important part of these emissions causes odor nuisance. These odorous substances not only have an irritant effect on human senses, but also include toxic materials that are damaging to human health. Food fermentation is an industrial process with a high frequency of odor emissions to the atmosphere that cause odor nuisance. With increasing population, and new residential and industrial developments, the demand for volatile organic compound (VOC) and odor control systems has been driven urgently. In addition to the stricter environmental regulations, the encroachment of residential areas on industrial facilities and increasing public expectations have resulted in an increase in the number of public odor complaints during the last decades [1], [2]. Stringent environmental legislations enforced by government agencies have led polluting industries to adopt effective air pollution treatment processes in order to comply with these regulations. Also, Turkey enacted the "Regulation on Control of Emissions that Contribute to Odor (KOEKHY)", which came into force as of July 19, 2013. Within this regulation, industrial facilities must 
control their odorous emissions and if they exceed the legal limits, which were determined by this regulation, the industry is obligated to treat the emissions with proper control systems and provide standards according to KOEKHY [3].

The yeast fermentation process, which is a part of the food industry, causes intensive odorous-compound formation. Ethanol and acetaldehyde, which are VOCs, are released into the ambient air from this process and lead to stack odor problems. Odor threshold values were recorded between 5 and $500 \mathrm{ppbV}$, and between 10 and $120 \mathrm{ppbV}$ for ethanol and acetaldehyde, respectively [4]. With the strict regulation for odor pollution, the determination of odor and the treatment of odorous compounds became important and instrumental analyses and olfactometric odor determination methods were found to be the most representative methods for odor-pollution characterization [5]. In this way, gas chromatography is the most common method used to differentiate between very similar compounds in a mixture. The components that are present in a gas mixture can be found by using this method in a short time period with high sensitivity. When definite quantitative and qualitative results are needed, a mass spectrometer coupled to the gas chromatograph is used [6].

Olfactometric measurement is a subjective method for the determination of odorous compounds. The olfactometer utilizes the 'yes/no' principle, in which the panelists have two different probes, one for the gas sample and the other for an odor-free blank gas to compare with. The number of dilutions required for a positive detection by $50 \%$ of the panelists defines the odor concentration in odor units of emissions per cubic meter $\left(\mathrm{OUE} / \mathrm{m}^{3}\right)$ [7], [8].

Until now, several physical-chemical treatment technologies such as incineration, catalytic oxidation and adsorption have been used for the abatement of VOC emissions [9]. However, the high capital and operating costs associated with these technologies, their high energy requirements and non-environmentally friendly nature have boosted the development of new treatment alternatives. At this point of context, biological treatment alternatives such as biofilters, bioscrubbers and biotrickling filters have come into prominence [10]. These biological systems are well-established technologies for the abatement of dilute VOC emissions $\left(<2000 \mathrm{mg} \mathrm{m}^{-3}\right)$ [11], [12]. Apart from other biological treatment technologies, biofilters offer advantages due to their high flowrate waste gas treatment capacities over other technology alternatives.

Within this study, both objective and subjective odor pollution analyses were carried out, the odor levels and characteristics present in the food fermentation process were determined, and a pilot-scale biofilter operation was performed for the characterized food fermentation emissions.

\section{MATERIALS AND METHODS}

\subsection{Characterization of food fermentation emissions}

In order to determine odorous emissions at waste gas streams of the fermentation process, an active sampling method was conducted based on the principle of air flow in sorbent tubes using a pump system. Sorbent tubes contained the sorbent material 20:35 Tenax-TA ${ }^{\mathrm{TM}}, 60: 80$ Carboxen $^{\mathrm{TM}} 1000$, and 60:80 Carbosieve ${ }^{\mathrm{TM}}$ SIII that were found appropriate for expected VOCs. Analyses were conducted for 30 seconds during active sampling with a flowrate of $100 \mathrm{ml} / \mathrm{min}$, which facilitated the adsorption of VOCs generated during the food fermentation process. Samples were taken in duplicates every hour in order to present a complete cycle of fermentation emissions for 17 hours. Collected waste gas samples were analyzed within 24 hours on an Agilent 7890A, 5975C-Tripleaxes GS/MS system and a HP5MS $(30 \mathrm{~m} \times 0.25 \mathrm{~mm} \times 0.25 \mu \mathrm{m})$ column, using the pre-concentration equipment of a thermal 
desorber (CDS 9300) for 10 minutes at $250^{\circ} \mathrm{C}$ in order to measure VOCs using the gas chromatography-mass spectrometry (GC-MS) system in the best way possible and to have representative measurement results from them.

In order to determine the odor threshold level $(50 \%$ of people can detect the odor) in people, dynamic olfactometry measurements were done according to EN 13725:2003 standards. Samples were collected into $1 \mathrm{~L}$ Tedlar Bags and were analyzed by the accredited panelists on ECOMA TO8 Olfactometry within 24 hours in order to determine odor threshold level and odor strength. During olfactometric measurement, the collected waste gas samples were diluted up to a maximum of 64,000 times, and an odorous mixture and an odor-free gas were sniffed by panelists. The detection level and type of the odor were determined.

\subsection{Biofilter operation procedure}

\subsubsection{A pilot scale biofilter}

A pilot scale biolfilter system that consisted of a cylindrical jacketed PVC column $(0.20 \mathrm{~m}$ inner diameter, $2.7 \mathrm{~m}$ height) packed with Rashing rings to a working volume of $50 \mathrm{~L}$ was inoculated with activated sludge from the recycling line of the wastewater treatment plant of Ambarli (Istanbul, Turkey). Some $8 \mathrm{~L}$ of the activated sludge with a volatile suspended solid (VSS) concentration of $12,500 \mathrm{mg} \mathrm{L}^{-1}$ were resuspended in $2000 \mathrm{ml}$ and added to the biofilter column that was packed with Rashing rings.

The synthetic inlet gas stream with a flowrate of $2 \mathrm{~m}^{-3} \mathrm{~h}^{-1}$ was prepared by injecting liquid ethanol via a syringe pump for solo pollution component experiments. The injection of a mixture of ethanol, acetaldehyde and acetone commenced on the $93^{\text {rd }}$ day of operation from the bottom of the column in a counter current mode with the trickling liquid flow, containing emissions at inlet concentrations of $\sim 700 \mathrm{mg} \mathrm{m}^{-3}$ for ethanol, $\sim 300 \mathrm{mg} \mathrm{m}^{-3}$ for acetaldehyde and $\sim 70 \mathrm{mg} \mathrm{m}^{-3}$ for acetone, according to the waste gas characterization of industrial processes.

The flow rate was controlled to maintain a gas empty-bed residence time of 80 seconds. Irrigation liquid includes all nutrients and was composed of $\left(\mathrm{g} \mathrm{L}^{-1}\right): \mathrm{Na}_{2} \mathrm{HPO}_{4} \cdot 12 \mathrm{H}_{2} \mathrm{O}, 6.15$; $\mathrm{KH}_{2} \mathrm{PO}_{4}, 1.52 ; \mathrm{MgSO}_{4} \cdot 7 \mathrm{H}_{2} \mathrm{O}, 0.2 ; \mathrm{CaCl}_{2}, 0.038$; and $10 \mathrm{~mL} \mathrm{~L}{ }^{-1}$ of a trace element solution containing $\left(\mathrm{g} \mathrm{L}^{-1}\right)$ : EDTA, 0.5; $\mathrm{FeSO}_{4} \cdot 7 \mathrm{H}_{2} \mathrm{O}, 0.2 ; \mathrm{ZnSO}_{4} \cdot 7 \mathrm{H}_{2} \mathrm{O}, 0.01 ; \mathrm{MnCl}_{2} \cdot 4 \mathrm{H}_{2} \mathrm{O}, 0.003$; $\mathrm{H}_{3} \mathrm{BO}_{3}, 0.03 ; \mathrm{CoCl}_{2} \cdot 6 \mathrm{H}_{2} \mathrm{O}, 0.02 ; \mathrm{CuCl}_{2} \cdot 2 \mathrm{H}_{2} \mathrm{O}, 0.001 ; \mathrm{NiCl}_{2} \cdot 6 \mathrm{H}_{2} \mathrm{O}, 0.002 ; \mathrm{NaMoO}_{4} \cdot 2 \mathrm{H}_{2} \mathrm{O}$, 0.003 [13].

\section{RESULTS AND DISCUSSION}

\subsection{Characterization of food fermentation emissions}

According to chromatographic instrumental analyses, the food fermentation process in question resulted in the emission of gases containing VOCs such as ethanol, acetaldehyde, and 1-propanol to the atmosphere, thereby causing an odor problem (Table 1). In this context, volatile compounds of alcohol, which accounted for more than $99 \%$ of the emissions and caused this odor in the fermentation process, were analyzed.

According to the results that were obtained, the measurements showed clearly that the first hours of the fermentation process were accountable for emission concentrations varying between $1000 \mathrm{mg} / \mathrm{m}^{3}$ and $1200 \mathrm{mg} / \mathrm{m}^{3}$ for the VOCs in the alcohol group. Emissions declined dramatically after the $10^{\text {th }}$ hour of fermentation. It was recorded that the cycle was completed as of the $13^{\text {th }}$ hour of the process and the emission rate was negligible until the $17^{\text {th }}$ hour (Fig. 1). The waste gas characteristics of the fermentation process were found to comprise 
$70-75 \%$ ethanol emissions, $25-30 \%$ acetaldehyde emissions and $\leq 5 \%$ other VOCs such as acetone and propanol.

Within the odor threshold data in the literature, analytical results were converted in terms of odor concentration unit $\left(\mathrm{OU} / \mathrm{m}^{3}\right)$ and emissions have been found 30,000 times higher than odor threshold levels from the literature. Dynamic field olfactometry results supported the theoretical calculations and the emissions from food fermentation processes analyzed by panelists resulted in a range of values between $28,090 \mathrm{UO} / \mathrm{m}^{3}$ and $39,725 \mathrm{UO} / \mathrm{m}^{3}$.

Table 1: Time course of food fermentation cycle emissions.

\begin{tabular}{llllll}
\hline $\begin{array}{l}\text { Fermentation } \\
\text { cycle }(\mathrm{h})\end{array}$ & $\begin{array}{l}\text { Ethanol } \\
\left(\mathrm{mg} / \mathrm{m}^{3}\right)\end{array}$ & $\begin{array}{l}\text { Acetone } \\
\left(\mathrm{mg} / \mathrm{m}^{3}\right)\end{array}$ & $\begin{array}{l}\text { Propanol } \\
\left(\mathrm{mg} / \mathrm{m}^{3}\right)\end{array}$ & $\begin{array}{l}\text { Acetaldehyde } \\
\left(\mathrm{mg} / \mathrm{m}^{3}\right)\end{array}$ & $\begin{array}{l}\text { Total emission } \\
\left(\mathrm{mg} / \mathrm{m}^{3}\right)\end{array}$ \\
\hline 1 & 764 & 65 & 16 & 331 & 1176 \\
3 & 704 & 54 & 20 & 275 & 1053 \\
4 & 720 & 58 & 21 & 290 & 1089 \\
5 & 634 & 44 & 18 & 215 & 910 \\
6 & 629 & 38 & 18 & 197 & 880 \\
7 & 720 & 47 & 22 & 224 & 1013 \\
8 & 612 & 39 & 17 & 197 & 866 \\
9 & 663 & 34 & 15 & 172 & 885 \\
10 & 396 & 23 & 11 & 110 & 539 \\
11 & 359 & 31 & 6 & 145 & 540 \\
13 & 109 & 10 & 1 & 43 & 162 \\
15 & 1 & 2 & 0 & 5 & 7 \\
17 & 0 & 0 & 0 & 0 & 0 \\
\hline
\end{tabular}

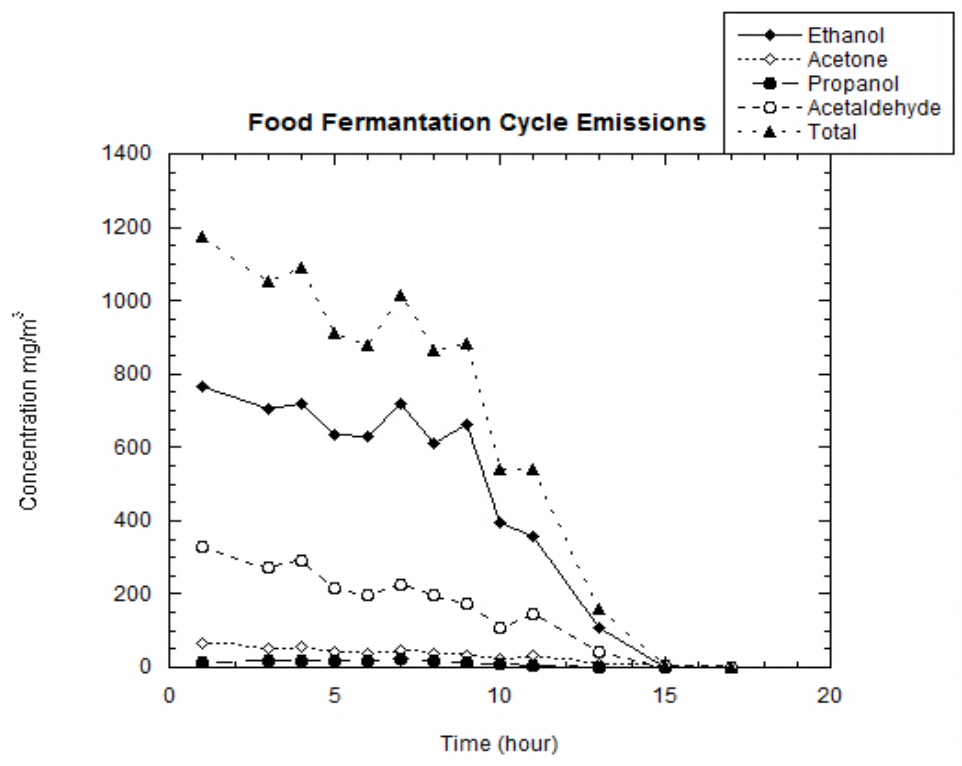

Figure 1: Change of food fermentation process emissions versus time. 
According to Turkish legislation, industries that have odor emissions higher than $10,000 \mathrm{UO} / \mathrm{m}^{3}$ have to decrease their emissions to below $1000 \mathrm{UO} / \mathrm{m}^{3}$. In this context, the biotreatment of VOCs is pointed to as the first treatment alternative due to its environmentally friendly nature and offering low-cost alternative technologies. Biological systems such as biofilters, bioscrubbers and biotrickling filters are well-established technologies for VOC removal in low-concentrated streams. Due to the high hydrophilic character of the emissions and high flowrate streams, biofilters are suggested as an ideal treatment technology for food fermentation processes.

\subsection{Biofilter operation results}

The biofilter system was operated for 143 days. From day 0 to 91 , system operation was performed for solo ethanol removal with a concentration of $700 \mathrm{mg} / \mathrm{m}^{3}$ and a flowrate of $2 \mathrm{~m}^{3} / \mathrm{h}$. The initial steady-state ethanol removal efficiency reached up to $95 \%$ within elimination capacity of $28 \mathrm{~g} \mathrm{~m}^{-3} \mathrm{~h}^{-1}$ (Fig. 2). A liquid mineral salt medium was used to periodically irrigate the column in order to supply humidity to the biofilter column.

On the $90^{\text {th }}$ day of operation, a mass transfer test was carried out in order to understand if the system was limited either by mass transfer or by biological activity. Inlet concentration was doubled and hourly samples were taken and analyzed at GC-MS. The higher inlet load clearly showed that biofilter performance was limited by the transport of these target compounds and the system was capable of removing more emissions. After the $91^{\text {st }}$ day of operation, all emissions were added to the synthetic waste gas stream. High removal efficiency was observed for acetaldehyde and removed with $90 \%$ efficiency, and an average elimination capacity of $10 \mathrm{~g} \mathrm{~m}^{-3} \mathrm{~h}^{-1}$ where acetone could be only partly removed after an adaptation of 15 days with an average removal of $65 \%$, and only $2 \mathrm{~g} \mathrm{~m}^{-3} \mathrm{~h}^{-1}$ of elimination capacity was noticed (Fig. 3). Ethanol removal slightly decreased compared to the previous steady-state conditions and still $90 \%$ removal was observed. On the $38^{\text {th }}$ day of operation at the second steady state, flowrate was increased to $3 \mathrm{~g} \mathrm{~m}^{3} \mathrm{~h}^{-1}$ and resulted in a dramatic decrease of acetone removal - only half of the acetone could be removed successfully where ethanol and acetaldehyde were removed with same rate. After the $51^{\text {st }}$ day of operation, the system operation was finished.

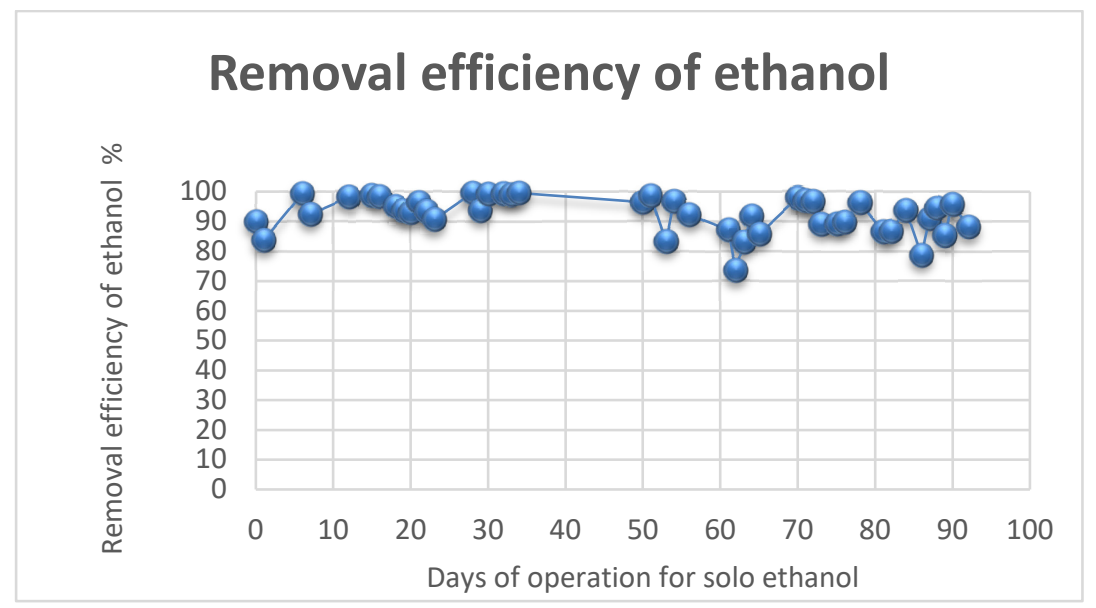

Figure 2: Ethanol removal as single component. 


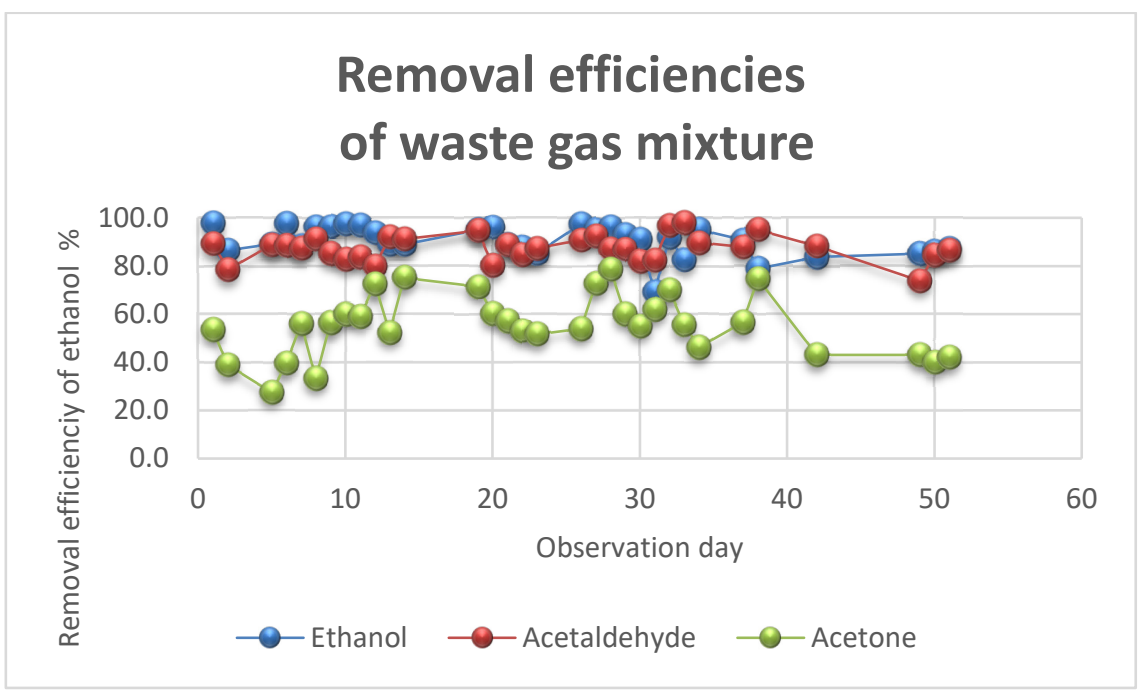

Figure 3: Waste gas mixture removals.

\section{ACKNOWLEDGEMENTS}

This study has been carried out with the support of the Turkish Scientific and Technological Research Council of Turkey for the project "112Y273 Removal of odor emissions from food fermentation and petrochemical production processes with using bioscrubber and biofilter".

\section{REFERENCES}

[1] Easter, C., Witherspoon, J., Voig, R. \& Cesca, J., An odor control master planning approach to public outreach programs. Proceedings of the 3rd IWA International Conference on Odour and VOCs, Barcelona, 2008.

[2] Stuetz, R.M. \& Frechen, F.B., Odours in Wastewater Treatments: Measurement, Modelling and Control, IWA Publishing: Cornwall, 2001.

[3] Ministry of Environment \& Forests, Govt. of India, Guidelines on odor pollution \& its control, 2012.

[4] Fazzalari, F.A., Compilation of odor and taste threshold data, ASTM Data Series DS 48A, 1978.

[5] Stratejilerinin Geliştirilmesi, Yüksek Lisans Tezi, İstanbul Teknik Üniversitesi.

[6] Guvener, M., Investigation of odorous emissions and immissons in Ankara with olfactometer, Master's thesis, ODTU, 2004.

[7] European Council BS EN 13725, Air quality. Determination of odor concentration by dynamic olfactometry, 2003.

[8] ASTM, D6196-03, Standard Practice for Selection of Sorbents, Sampling, and Thermal Desorption Analysis Procedures for Volatile Organic Compounds in Air, ASTM International: West Conshohocken, PA, 2009. DOI: 10.1520/D6196-03R09.

[9] Chen, J.M., Zhu, R.Y., Yang, W.B. \& Zang, L.L., Treatment of a BTo-X-contaminated gas stream with a biotrickling filter inoculated with microbes bound to a wheat bran/red wood powder/diatomaceous earth carrier. Bioresource Technology, 101, pp. 8067-8073, 2010. 
[10] Akmirza, I., Pascual, C., Carvajal, A., Perez, R., Munoz, R. \& Lebrero, R., Anoxic Biodegradation of BTEX in a biotrickling filter. Science of Total Environment, 587588, pp. 457-465, 2017.

[11] Balasubramanian, P., Philip, L. \& Bhallamudi, S.M., Biotrickling filtration of VOC emissions from pharmaceutical industries. Chemical Engineering Journal, 209, pp. 102-112, 2012.

[12] Estrada, J., Kraakman, N.J.R., Muñoz, R. \& Lebrero, R., A comparative analysis of odour treatment technologies in wastewater treatment plants. Environmental Science and Technology, 45, pp. 1100-1106, 2011.

[13] Muñoz, R., Souza, T.S.O., Glittmann, L., Pérez, R. \& Guillermo, G., Biological anoxic treatment of $\mathrm{O}_{2}$-free VOC emissions from the petrochemical industry: A proof of concept study. Journal of Hazardous Materials, 260, pp. 442-450, 2013. 